\title{
Safety Evaluation of Turmeric Polysaccharide Extract: Assessment of Mutagenicity and Acute Oral Toxicity
}

\author{
Chandrasekaran Chinampudur Velusami, Srinivasa Rao Boddapati, \\ Srikanth Hongasandra Srinivasa, Edwin Jothie Richard, Joshua Allan Joseph, \\ Murali Balasubramanian, and Amit Agarwal
}

\author{
R\&D Centre, Natural Remedies Private Limited, 5B, Veerasandra Indl. Area, 19th K. M. Stone, \\ Hosur Road, Electronic City Post, Bangalore 560100, Karnataka, India
}

Correspondence should be addressed to Chandrasekaran Chinampudur Velusami; cvc@naturalremedy.com

Received 5 September 2013; Revised 26 November 2013; Accepted 26 November 2013

Academic Editor: Marina Soković

\begin{abstract}
Copyright (C) 2013 Chandrasekaran Chinampudur Velusami et al. This is an open access article distributed under the Creative Commons Attribution License, which permits unrestricted use, distribution, and reproduction in any medium, provided the original work is properly cited.
\end{abstract}

Curcuma longa Linn. (Zingiberaceae) commonly known as turmeric has long been used for centuries as a spice and household remedy. The present study was carried out to assess the possible mutagenic potential and acute oral toxicity of polysaccharide extract of turmeric rhizome (NR-INF-02) using standard tests. The standard battery of in vitro genotoxicity tests, bacterial reverse mutation test (BRMT), chromosome aberration (CA), and micronucleus (MN) tests were employed to assess the possible mutagenic activity of NR-INF-02 (Turmacin). The results showed no mutagenic effect with NR-INF-02 up to a dose of 5000 $\mu \mathrm{g} / \mathrm{mL}$ in BRMT. The results on CA and MN tests revealed the non clastogenic activity of NR-INF-02 in a dose range of 250.36 to $2500 \mu \mathrm{g} / \mathrm{mL}$ with and without metabolic activation (S9). In acute oral toxicity study, NR-INF-02 was found to be safe up to $5 \mathrm{~g} / \mathrm{kg}$ body weight in Wistar rats. Overall, results indicated that polysaccharide extract of $C$. longa was found to be genotoxically safe and also exhibited maximum tolerable dose of more than $5 \mathrm{~g} / \mathrm{kg}$ rat body weight.

\section{Introduction}

Turmeric (Curcuma longa) has been used for centuries in Ayurvedic medicine, which amalgamate the medicinal goods of herbs with food. This astonishing herb has established its way into the attention in the west because of its wide range of medicinal benefits [1]. In ayurveda, rhizome of turmeric is used as medicines against skin, gastrointestinal, respiratory, hepatic, and biliary disorders [2]. The active constituents of C. longa are the flavonoid curcumin (diferuloylmethane) and various volatile oils, including tumerone, atlantone, and zingiberene. Other constituents include sugars, proteins, and resins. The best researched active constituent is curcumin, which comprises 0.3-5.4 percent of raw turmeric [1]. Components of turmeric especially curcumin has been shown to have anti-inflammatory, antiviral, and anticancer properties [3-5]. Among the phytoconstituents of C. longa, curcuminoids are considered as an important active molecule and also exhibited wide range of pharmacological activities. The literature review confirmed plethora of information available on safety aspects of curcumin and essential oil fractions of $C$. longa $[3,6-8]$.

While curcuminoids based extract were well studied for their pharmacological and safety aspects, polysaccharide extract of C. longa is gaining importance since it showed to have various pharmacological activities, which include antidiabetic, antitumour, antidepressant, antioxidant, antimicrobial, antifertility, hepatoprotective, and immunomodulatory properties [9-16]. NR-INF-02, a polysaccharide extract prepared from rhizome of $C$. longa had shown clinical efficacy in a randomized placebo controlled study on 120 human patients ( 37 males and 83 females) affected with primary osteoarthritis [17]. NR-INF-02 deserved as an effective option for the treatment of patients with primary painful knee and joint pains and also reduced the need of analgesics as a rescue medication [17]. Also, NR-INF-02 showed immunestimulatory and anti-inflammatory effects in in vitro models 
by influencing various cytokines involved in immune regulation [18]. Similarly, the immunostimulatory effects of $C$. longa polysaccharides on peripheral blood mononuclear cells was investigated and the findings revealed the potential use of $C$. longa polysaccharide extract as an adjuvant supplement for cancer patients, whose immune activities were suppressed during chemotherapies [16].

Polysaccharide extract of C. longa needs evaluation for their safety due to its growing demand on reported preclinical therapeutic indications. Also, before setting of a clinical trial of an herbal product, its safety must be evaluated by toxicity test procedures. Also, this toxicity evaluation is helpful for the estimation of an initial safe starting dose and dose range for the human trials and the identification of parameters for clinical monitoring for potential adverse effects. Hence, the goal of the present investigation is to characterize the toxicological profile of polysaccharide extract from C. longa rhizome (NR-INF-02).

In order to evaluate toxicological profile, the ability of NR-INF-02 to induce mutations was assessed in indicator microorganisms using bacterial reverse mutation test. The effect of NR-INF-02 on the genetic system was weighed up by analyzing induced chromosomal aberrations and micronucleus in mammalian cells. An acute oral toxicity study was performed after single oral dose of NR-INF-02 to determine immediate toxic effect. All these tests were conducted based on recommendation of the OECD guidelines [19-22].

\section{Materials and Methods}

2.1. Collection and Identification of Curcuma longa. The rhizomes of Curcuma longa Linn. were collected from different parts of Tamil Nadu State, India and authenticated at NISCAIR (National Institute of Science Communication and Information Resources). A voucher specimen (no. 653) was deposited in our herbarium.

2.2. Preparation of Polysaccharide Extract of Curcuma longa Extract (NR-INF-02). NR-INF-02 is manufactured and registered as Turmacin by Natural Remedies Pvt. Ltd., Bangalore, India. Coarsely powdered rhizomes of $C$. longa were subjected to steam distillation and the turmeric oil was separated and collected. The rhizomes were further extracted by refluxing with water in a commercial extraction facility. The liquid water extract was concentrated by distillation under vacuum and the resultant concentrated liquid was spray dried to obtain a free flowing powder. NR-INF-02 was prepared by blending 99 parts of spray dried water extract of C. longa and 1 part of the turmeric oil followed by sieving. Yield of this extract is $10.5 \% \mathrm{w} / \mathrm{w}$.

Details about the preparation and characterization of NR-INF-02 were described as earlier [18]. In brief, NRINF-02 was standardized to contain polysaccharides $(>10 \%$ w/w) by high performance liquid chromatography [23]. As reported previously, NR-INF-02 was found to contain negligible amount of curcumin [18]. NR-INF-02 was assessed for presence and absence of microbial (total aerobic microbial count, total yeast and mould count, bile tolerant gram negative bacteria, E. coli, Salmonella species, S. aureus), heavy metals (lead, arsenic, cadmium, and mercury), pesticides (75 different pesticides), and aflatoxin levels as per the method described by the United States Pharmacopeia [24]. Results indicated that NR-INF-02 is compliant to the limit set by United States Pharmacopeia (USP) and British Pharmacopeia $[24,25]$. Stability of NR-INF-02 was assessed using accelerated and real time protocols of ICH guidelines [26]. NR-INF02 did not undergo any major changes (physically, chemically, and microbiologically) when stored under accelerated and real time condition for 6 months and 12 months, respectively. Based on the stability study it is recommended to store NRINF- 02 below $30^{\circ} \mathrm{C}$ in an airtight container.

2.3. Source of Chemicals. 2-aminoanthracene (2-AA), benzo[a]pyrene, colchicine, cytochalasin B, D-glucose-6phosphate, 3-(4,5Dimethylthiazol-2-yl)-2,5-diphenyltetrazolium bromide, nicotinamide adenine dinucleotide phosphate, mitomycin C, 2-nitrofluorene (2-NF), 4-nitroquinolene-N-oxide (4-NQO), phytohemagglutinin, potassium chloride $(\mathrm{KCl})$ were purchased from Sigma-Aldrich. Fetal bovine serum (FBS) was procured from Hyclone. Aroclor 1254 induced S9 fraction was obtained from Moltox. The Ames II Automated System for High Throughput Screening kit containing Salmonella strains like TA98 strain and TAMix strain, ampicillin, exposure medium incubation bag, indicator medium and growth medium were purchased from Xenometrix. Ham's F12K medium, RPMI 1640 medium and Trypsin-EDTA were purchased from Gibco Life Technologies.

2.4. Bacterial Strains and Mammalian Cells. The bacterial reverse mutation test (Ames II) was performed using Salmonella typhimurium histidine auxotrophs, TA98 strain and TAMix strain. Genotyping on Salmonella strains like TA98 strain and TAMix strain was confirmed before conducting the mutagenicity study. Concentration of standard mutagen(s), S9 and incubation time were optimized and selected based on previous publications [27-31] which we have followed in the current genotoxicity study. $10 \mu \mathrm{L}$ of freshly thawed frozen Salmonella strains like TA98 strain and TAMix strain were inoculated to $10 \mathrm{~mL}$ of growth medium and the cultures were grown overnight at $37^{\circ} \mathrm{C}$ in an environmental shaker set at $180 \mathrm{rpm}$ in the presence of ampicillin $(50 \mu \mathrm{g} / \mathrm{mL})$. The human peripheral blood for chromosome aberration study was collected from healthy human volunteers. Lymphocytes of human peripheral blood cells were cultured in RPMI 1640 media supplemented with $20 \%$ heat-inactivated fetal bovine serum (FBS) and $2 \%$ phytohemagglutinin- $\mathrm{M}$ for $48 \mathrm{~h}$ in culture tubes fitted with loose caps at $37^{\circ} \mathrm{C}$ in a humidified atmosphere of $5 \% \mathrm{CO}_{2}$. Chinese Hamster Ovary cells (CHO-K1) for micronucleus test was procured from American Type Culture Collection. $\mathrm{CHO}-\mathrm{K} 1$ cells were cultured in Ham's F12K media supplemented with $10 \% \mathrm{FBS}$, in $37^{\circ} \mathrm{C}$ incubator maintained at $5 \%$ $\mathrm{CO}_{2}$.

2.5. Bacterial Reverse Mutation Test. The bacterial reverse mutation test (Ames II) was used to identify the ability of test substance to induce reverse mutation at histidine loci 
in Salmonella strains like TA98 strain and TAMix strain (mixture of six base pair mutant strains TA7001-7006). This mutagenicity test was performed according to standard procedure [19, 27-32]. Briefly, Salmonella typhimurium tester strains like TA98 strain and TAMix strain were exposed to NR-INF-02 by fluctuation method with and without S9. Dulbecco's Phosphate Buffered Saline (DPBS) was used to solubilise NR-INF-02 and also designated as a vehicle control. NR-INF-02 at a maximum concentration of $5000 \mu \mathrm{g} / \mathrm{mL}$ and subsequent concentrations, $1582.28,500.72,158.46,50.14$, and $15.87 \mu \mathrm{g} / \mathrm{mL}$ were selected to assess the mutagenic effect. NR-INF-02 at concentration range of 15.87 to $5000 \mu \mathrm{g} / \mathrm{mL}$, Salmonella tester strain like TA98/TAMix strain with and without S9 mix were added along with reversion indicator media into the wells of 384-well plates and incubated for $48 \mathrm{~h}$ at $37^{\circ} \mathrm{C}$. All doses of the NR-INF-02, vehicle control (DPBS), and positive controls were plated in triplicates; 2$\mathrm{NF}(2 \mu \mathrm{g} / \mathrm{mL})+4-\mathrm{NQO}(0.5 \mu \mathrm{g} / \mathrm{mL})$ and $2-\mathrm{AA}(5 \mu \mathrm{g} / \mathrm{mL})$ were used as positive controls in the absence and presence of S9 respectively. After incubation, the revertant colonies were counted and positive response was determined by significant increase in the mean revertant per plate of atleast one of the tester strains as compared to vehicle control.

2.6. Chromosome Aberration Assay Using Human Peripheral Blood Lymphocytes. Chromosome aberration test was performed as per OECD guideline no. 473 [20]. Human blood was collected aseptically from one healthy, non-smoking male donor. $0.5 \mathrm{~mL}$ of blood, $9.5 \mathrm{~mL}$ growth medium (RPMI $1640+20 \%$ heat inactivated fetal bovine serum) were added and cultured using phytohemagglutinin-M (2\% v/v) for $48 \mathrm{~h}$ at $37^{\circ} \mathrm{C}$ in a humidified atmosphere of $5 \% \mathrm{CO}_{2}$ in air. The cultures were gently shaken daily. After $48 \mathrm{~h}$, cells were treated with NR-INF-02 $(250.35,791.14,2500 \mu \mathrm{g} / \mathrm{mL})$ in presence and absence of S9. NR-INF-02 at a maximum concentration of $2500 \mu \mathrm{g} / \mathrm{mL}$ was used since it did not produce evident cytotoxicity to human lymphocytes. RPMI 1640 medium was used to dissolve NR-INF-02 and also designated as vehicle control. Mitomycin C $(0.2 \mu \mathrm{g} / \mathrm{mL})$ was used as positive control for both short term $(4 \mathrm{~h})$ and long term ( $36 \mathrm{~h})$ exposure studies in the absence of S9, whereas, benzo[a]pyrene $(20 \mu \mathrm{g} / \mathrm{mL})$ was used as positive control for short term exposure $(4 \mathrm{~h})$ study only with S9. After short term exposure, the treatment medium was removed by centrifugation and cultures replenished with growth medium (RPMI $1640+10 \%$ FBS). The cells were again returned to the incubator to complete 1.5 cell cycle lengths. For long term, the cells are treated with test compound for the entire 1.5 cell cycle length. Cells were exposed to colchicine $(0.3 \mu \mathrm{g} / \mathrm{mL})$ for $3 \mathrm{~h}$ prior to harvest. After $3 \mathrm{~h}$, cells were centrifuged, resuspended in hypotonic medium $(75 \mathrm{mM} \mathrm{KCl})$ and fixed (prechilled, 3 parts of ethanol and 1 part of glacial acetic acid). Approximately 3-4 drops of the fixed cell suspension from the height of $30 \mathrm{~cm}$ was dropped onto a clean microscope slide and stained with $10 \%$ Giemsa solution for $10 \mathrm{~min}$. Two hundred metaphase chromosome spreads per treatment were examined under the microscope for chromosome break, chromatid break, deletion, ring, dicentric and rearrangements as indicated by
Savage [33]. Only metaphases containing $46 \pm 2$ centromeres (chromosomes) were considered for analysis. The number of cells with aberrations and the number of aberrations were recorded. Experiments were performed in duplicates per treatment. Cytotoxicity was determined by calculating Mitotic index (MI) according to the formula

$$
\text { percent } \mathrm{MI}=\left(\frac{\text { no. of cells in metaphase }}{\text { total number of cells }}\right) \times 100 \text {. }
$$

2.7. In Vitro Micronucleus Test in Chinese Hamster Ovary (CHO-K1) Cells. Micronucleus test was carried out according to the OECD guideline no. 487 [21]. CHO-K1 cells were incubated with NR-INF-02 $(250.36 \mu \mathrm{g} / \mathrm{mL}, 791.14 \mu \mathrm{g} / \mathrm{mL}$ and $2500 \mu \mathrm{g} / \mathrm{mL})$ in both short $(4 \mathrm{~h})$ and long term $(18 \mathrm{~h})$ exposure studies with and without S9. Ham's F12K media was used to solubilise NR-INF-02 and also designated as a vehicle control. Mitomycin C $(0.2 \mu \mathrm{g} / \mathrm{mL})$ was used as positive control in the absence of $\mathrm{S} 9$ for both short and long term exposure studies. Benzo[a]pyrene $(20 \mu \mathrm{g} / \mathrm{mL})$, was used only with $\mathrm{S} 9$ in a short term exposure study. After short term exposure, treatment medium was removed by aspiration and the cells were rinsed with Hank's balanced salt solution (HBSS) and replenished with complete Ham's F12 medium containing cytochalasin B $(3 \mu \mathrm{g} / \mathrm{mL})$ to arrest cytoplasmic division of the cells. The cells were then returned to the incubator for an additional $18 \mathrm{~h}$. For long term study, NR-INF-02 and cytochalasin B were added together and incubated for $18 \mathrm{~h}$. After trypsinization, cells were suspended in $75 \mathrm{mM} \mathrm{KCl}$ and fixed using precooled fixative [ethanol and glacial acetic acid $(3: 1)]$. Approximately $3-4$ drops of the cell suspension were dropped from the height of $5 \mathrm{~cm}$ onto a clean microscope slide. The slides were air dried overnight and stained with $10 \%$ Giemsa for $10 \mathrm{~min}$. Experiments were performed in duplicates. The criteria for selecting the binucleated cells were based on the report by Fenech [34]. Per treatment, 2000 cytoplasm division arrested cells were examined for the presence of micronucleus. Cytokinesis Block Proliferation Index (CBPI) was determined to calculate the cell toxic effect of treatment according to the formula

$$
\begin{aligned}
\mathrm{CPBI}= & (\text { no. of mononucleated cells } \\
& +2(\text { no. of binucleated cells }) \\
& +3(\text { no. of multinucleate cells })) \\
& \times(\text { total number of cells })^{-1}
\end{aligned}
$$

2.8. Acute Oral Toxicity. The animal experiment was conducted according to the CPCSEA (Committee for the Purpose of Control and Supervision of Experiments on Animals) guidelines and after approval by the Institutional Animal Ethics Committee (IAEC). Female albino Wistar rats (812 weeks) were accommodated in polypropylene cages and temperature was maintained between $25 \pm 2^{\circ} \mathrm{C}$ with $12 \mathrm{~h}$ each of dark and light cycle. The rats were fed with standard laboratory pelleted feed (M/s Gold Mohur Foods \& Feeds Ltd., Bangalore, India). The rats were fasted overnight before and $3 \mathrm{~h}$ after the administration of NR-INF-02. Acute oral toxicity 
study was performed as per the OECD Guideline for the Testing of Chemicals (Test no. 420, Section 4: Health Effects) Acute Oral Toxicity-Fixed Dose Procedure [22]. NR-INF02 solubilized in demineralized water was administered by oral route to rats at the limit dose of $5 \mathrm{~g} / \mathrm{kg}$ body weight in a sequential manner. On the day of dosing, all the animals were observed for mortality and clinical signs for first $10 \mathrm{~min}$, $30 \mathrm{~min}, 1 \mathrm{~h}, 2 \mathrm{~h}, 4 \mathrm{~h}$, and $6 \mathrm{~h}$ after dosing and thereafter twice daily for mortality and once a day for clinical signs, for 14 days. Animals were sacrificed at the end of the study period of 14 days.

2.9. Statistical Analysis. Data are expressed as mean \pm standard deviation (SD). One way analysis of variance (ANOVA) was performed on the results followed by a Dunnett's test for multiple comparisons using GraphPad Prism 5.0 (GraphPad Software, Inc., San Diego, CA) statistical software package. The significance level was chosen at $P<0.05$ for all statistical analyses in comparison to the respective vehicle control.

\section{Results}

3.1. Bacterial Reverse Mutation Test. To detect possible point mutations by NR-INF-02, histidine requiring mutants of S. typhimurium strains likeTA98 strain and TAMix strain, with and without S9 were used. No significant bacterial cell toxicity was observed after treatment with NR-INF-02 up to a maximum concentration of $5000 \mu \mathrm{g} / \mathrm{mL}$. The occurrence of spontaneous reversion for TA98 strain and TAMix strain is in agreement with previous reports [27-31]. ANOVA followed by Dunnett's multiple comparison tests indicated that treatment of NR-INF-02 at concentrations, namely, $15.87 \mu \mathrm{g} / \mathrm{mL}$, $50.14 \mu \mathrm{g} / \mathrm{mL}, 158.46 \mu \mathrm{g} / \mathrm{mL}, 500.72 \mu \mathrm{g} / \mathrm{mL}, 1582.28 \mu \mathrm{g} / \mathrm{mL}$, and $5000 \mu \mathrm{g} / \mathrm{mL}$, did not show any significant increase in the number of revertant colonies in both Salmonella strains like TA98 strain and TAMix strain with and without S9 when compared to vehicle control. Positive controls, $2-\mathrm{NF}+4$ NQO, 2-AA demonstrated a significant $(P<0.05)$ increase in the number of revertant colonies in the absence and presence of S9 respectively (Tables 1 and 2). These results confirmed the nonmutagenic property of NR-INF-02 in TA98 strain and TAMix strain of S. typhimurium.

\subsection{In Vitro Chromosome Aberration Analysis in Human} Peripheral Blood Lymphocytes. Mitotic index values indicated that NR-INF-02 at dose level, namely, $250.36 \mu \mathrm{g} / \mathrm{mL}$, $791.14 \mu \mathrm{g} / \mathrm{mL}$, and $2500 \mu \mathrm{g} / \mathrm{mL}$, did not produce cell toxicity in both short term $(4 \mathrm{~h})$ and long term exposure $(36 \mathrm{~h})$ with and without S9 (Tables 3, 4, and 5). Treated cells arrested at metaphase stage were analyzed for possible structural chromosomal aberrations. Exposure of NR-INF-02 at the indicated concentrations $(250.36 \mu \mathrm{g} / \mathrm{mL}, 791.14 \mu \mathrm{g} / \mathrm{mL}$ and $2500.0 \mu \mathrm{g} / \mathrm{mL}$ ) to human lymphocytes did not induce a statistically significant increase in the number of cells with chromosome aberrations in the absence and presence of S9 in both short and long term exposure studies. As determined by ANOVA followed by Dunnett's multiple comparison tests, vehicle control cultures had an insignificant number of structural chromosomal aberrations which were within the limit of published data $[28,30,31]$. The positive controls, mitomycin $\mathrm{C}$, and benzo[a]pyrene were found to induce statistically significant $(P<0.05)$ number of structural chromosomal aberrations, namely, chromosome break, chromatid break, deletion in absence and presence of $\$ 9$ respectively in human peripheral blood lymphocytes (Tables 3, 4 and 5).

3.3. In Vitro Micronucleus Analysis in CHO-K1 Cells. Statistical analysis (ANOVA followed by Dunnett's tests) indicated that CBPI values did not differ significantly between the tested concentrations of NR-INF-02 and vehicle control. Mitomycin $\mathrm{C}$ treatment showed significant $(P<0.05)$ reduction on viability of $\mathrm{CHO}-\mathrm{K} 1$ cells in both short term and long term exposure cultures as evident from decrease of CBPI values in comparison with vehicle control. In the micronucleus test, no statistically significant increase in the frequency of cells with micronucleus was observed upon treatment with NR-INF-02 at the indicated concentrations $(250.36 \mu \mathrm{g} / \mathrm{mL}$, $791.14 \mu \mathrm{g} / \mathrm{mL}$ and $2500 \mu \mathrm{g} / \mathrm{mL}$ ), in the presence and absence of S9, in both short ( $4 \mathrm{~h})$ and long term (18 h) exposure cultures. Vehicle control had an insignificant number of micronucleus which were within the limit of published data $[28,30,31]$. As evident, the positive controls mitomycin $\mathrm{C}$ and benzo[a]pyrene formed significant $(P<0.05)$ increase in the frequency of cells with micronucleus in absence and presence of S9 respectively. Percent micronucleated, binucleated cells, and CBPI values for all treatment cultures are presented in Table 6 .

3.4. Acute Oral Toxicity. NR-INF-02 was evaluated for its acute oral toxicity by administering as a single oral dose to albino Wistar rats. NR-INF-02 was administered orally in a sequential manner to five rats at the limit dose level of $5000 \mathrm{mg} / \mathrm{kg}$ body weight. On the day of dosing, all the animals were observed for mortality and clinical signs for first $10 \mathrm{~min}, 30 \mathrm{~min}, 1 \mathrm{~h}, 2 \mathrm{~h}, 4 \mathrm{~h}$, and $6 \mathrm{~h}$ after dosing and thereafter twice daily for mortality and once a day for clinical signs, for 14 days. The body weight of rats was recorded and weekly body weight gain was calculated. After the observation period of 14 days, all surviving rats were sacrificed and subjected to complete necropsy. The treated rats did not show any adverse clinical signs immediately following dosing and during the observation period of 14 days. In sighting and main studies, treatment with NR-INF-02 did not reveal any adverse effects on the body weight gain at first and second week of observation. Overall, the percent body weight gain during the complete 14 days observation period was found to be normal in all the treated animals. On necropsy, no major gross pathological changes were observed in NR-INF02 treated rats (Tables 7 and 8). Based on the findings of the present study, NR-INF-02 was found to be safe after oral administration as a single dose of $5000 \mathrm{mg} / \mathrm{kg}$ to female albino Wistar rats.

\section{Discussion}

This study is focused on characterization of toxicological properties of $C$. longa polysaccharide extract: mutagenicity, 
TABLE 1: Mutagenicity testing of NR-INF-02 in Salmonella typhimurium TA98 strain.

\begin{tabular}{|c|c|c|c|c|c|c|c|}
\hline \multirow{3}{*}{ Treatment } & \multirow{3}{*}{ Concentration $(\mu \mathrm{g} / \mathrm{mL})$} & \multicolumn{6}{|c|}{ Number of revertant colonies } \\
\hline & & \multirow{2}{*}{ S9 } & \multicolumn{3}{|c|}{ Individual colony counts } & \multirow{2}{*}{ Mean \pm S.D } & \multirow{2}{*}{$\begin{array}{l}\text { Fold increase } \\
\text { over baseline }\end{array}$} \\
\hline & & & $\mathrm{R} 1$ & $\mathrm{R} 2$ & R3 & & \\
\hline \multirow{12}{*}{ NR-INF-02 } & \multirow{2}{*}{15.87} & - & 8 & 6 & 7 & $7.00 \pm 1.00$ & 0.83 \\
\hline & & + & 7 & 5 & 7 & $6.33 \pm 1.15$ & 0.90 \\
\hline & \multirow{2}{*}{50.14} & - & 6 & 4 & 8 & $6.00 \pm 2.00$ & 0.71 \\
\hline & & + & 3 & 8 & 7 & $6.00 \pm 2.65$ & 0.86 \\
\hline & \multirow{2}{*}{158.46} & - & 7 & 6 & 8 & $7.00 \pm 1.00$ & 0.83 \\
\hline & & + & 5 & 8 & 2 & $5.00 \pm 3.00$ & 0.71 \\
\hline & \multirow{2}{*}{500.72} & - & 4 & 7 & 6 & $5.67 \pm 1.53$ & 0.67 \\
\hline & & + & 4 & 6 & 4 & $4.67 \pm 1.15$ & 0.67 \\
\hline & \multirow{2}{*}{1582.28} & - & 8 & 8 & 8 & $8.00 \pm 0.00$ & 0.95 \\
\hline & & + & 3 & 7 & 4 & $4.67 \pm 2.08$ & 0.67 \\
\hline & \multirow{2}{*}{5000.00} & - & 8 & 7 & 4 & $6.33 \pm 2.08$ & 0.75 \\
\hline & & + & 8 & 7 & 7 & $7.33 \pm 0.58$ & 1.05 \\
\hline \multirow{2}{*}{ Vehicle control } & \multirow{2}{*}{0} & - & 8 & 4 & 7 & $6.33 \pm 2.08$ & - \\
\hline & & + & 6 & 7 & 5 & $6.00 \pm 1.00$ & - \\
\hline Positive control 2-NF + 4-NQO & $2.00+0.50$ & - & 47 & 46 & 48 & $47.00 \pm 1.00^{*}$ & 5.58 \\
\hline Positive control 2-AA & 5.00 & + & 48 & 48 & 48 & $48.00 \pm 0.00^{*}$ & 6.85 \\
\hline
\end{tabular}

R: replicate; ${ }^{*} P<0.05$; 2-NF: 2-nitrofluorene; 4-NQO: 4-nitroquinoline-N-oxide; 2-AA: 2-aminoanthracene.

TABLE 2: Mutagenicity testing of NR-INF-02 in Salmonella typhimurium TAMix strain.

\begin{tabular}{|c|c|c|c|c|c|c|c|}
\hline \multirow{3}{*}{ Treatment } & \multirow{3}{*}{ Concentration $(\mu \mathrm{g} / \mathrm{mL})$} & \multicolumn{6}{|c|}{ Number of revertants colonies } \\
\hline & & \multirow{2}{*}{ S9 } & \multicolumn{3}{|c|}{ Individual colony counts } & \multirow{2}{*}{ Mean \pm S.D } & \multirow{2}{*}{$\begin{array}{l}\text { Fold increase } \\
\text { over baseline }\end{array}$} \\
\hline & & & $\mathrm{R} 1$ & $\mathrm{R} 2$ & $\mathrm{R} 3$ & & \\
\hline \multirow{12}{*}{ NR-INF-02 } & \multirow{2}{*}{15.87} & - & 0 & 2 & 0 & $0.67 \pm 1.15$ & 0.67 \\
\hline & & + & 0 & 0 & 0 & $0.00 \pm 0.00$ & 0.00 \\
\hline & \multirow{2}{*}{50.14} & - & 0 & 0 & 1 & $0.33 \pm 0.58$ & 0.33 \\
\hline & & + & 0 & 2 & 0 & $0.67 \pm 1.15$ & 0.37 \\
\hline & \multirow{2}{*}{158.46} & - & 0 & 0 & 2 & $0.67 \pm 1.15$ & 0.67 \\
\hline & & + & 2 & 1 & 2 & $1.67 \pm 0.58$ & 0.92 \\
\hline & \multirow{2}{*}{500.72} & - & 0 & 1 & 0 & $0.33 \pm 0.58$ & 0.33 \\
\hline & & + & 0 & 0 & 1 & $0.33 \pm 0.58$ & 0.18 \\
\hline & \multirow{2}{*}{1582.28} & - & 2 & 1 & 1 & $1.33 \pm 0.58$ & 1.33 \\
\hline & & + & 0 & 2 & 0 & $0.67 \pm 1.15$ & 0.37 \\
\hline & \multirow{2}{*}{5000.00} & - & 0 & 3 & 2 & $1.67 \pm 1.53$ & 1.67 \\
\hline & & + & 0 & 2 & 0 & $0.67 \pm 1.15$ & 0.37 \\
\hline \multirow{2}{*}{ Vehicle control } & \multirow{2}{*}{0} & - & 1 & 1 & 1 & $1.00 \pm 0.00$ & - \\
\hline & & + & 0 & 0 & 2 & $0.67 \pm 1.15$ & - \\
\hline Positive control 2-NF $+4-\mathrm{NQO}$ & $2.00+0.50$ & - & 48 & 48 & 48 & $48.00 \pm 0.00^{*}$ & 48.00 \\
\hline Positive control 2-AA & 5.00 & + & 45 & 41 & 47 & $44.33 \pm 3.06^{*}$ & 24.35 \\
\hline
\end{tabular}

R: replicate; ${ }^{*} P<0.05$; 2-NF: 2-nitrofluorene; 4-NQO: 4-nitroquinoline-N-oxide; 2-AA: 2-aminoanthracene.

clastogenicity, and acute oral toxicity. These evaluations are a fundamental part of the clinical study aimed at determining the risk/benefit ratio of its use in the field of human health and subsequently introducing this extract into dietary supplement practice. Hence, this study was conducted to investigate the possible genotoxic potential of NR-INF-02 using bacterial reverse mutation, chromosomal aberration and micronucleus tests.

The significance of the bacterial reverse mutation test has been clearly confirmed as a suitable primary test for the detection of potential mutagens and carcinogens, and since midseventies this assay has been routinely used as 
TABLE 3: Clastogenicity study upon short term exposure (4h) of NR-INF-02 in the absence of metabolic activation in human blood lymphocytes.

\begin{tabular}{|c|c|c|c|c|c|c|c|c|c|c|}
\hline \multirow[t]{2}{*}{ Treatment } & \multicolumn{2}{|c|}{ Vehicle control } & \multicolumn{2}{|c|}{$\begin{array}{c}\text { Positive control } \\
\text { MMC } \\
(0.20 \mu \mathrm{g} / \mathrm{mL})\end{array}$} & \multicolumn{2}{|c|}{$\begin{array}{c}\text { NR-INF-02 } \\
(2500.00 \mu \mathrm{g} / \mathrm{mL})\end{array}$} & \multicolumn{2}{|c|}{$\begin{array}{c}\text { NR-INF-02 } \\
(791.14 \mu \mathrm{g} / \mathrm{mL})\end{array}$} & \multicolumn{2}{|c|}{$\begin{array}{c}\text { NR-INF-02 } \\
(250.36 \mu \mathrm{g} / \mathrm{mL}\end{array}$} \\
\hline & $\mathrm{R} 1$ & $\mathrm{R} 2$ & $\mathrm{R} 1$ & $\mathrm{R} 2$ & $\mathrm{R} 1$ & $\mathrm{R} 2$ & $\mathrm{R} 1$ & $\mathrm{R} 2$ & $\mathrm{R} 1$ & $\mathrm{R} 2$ \\
\hline Total number of metaphase analyzed & 100 & 100 & 100 & 100 & 100 & 100 & 100 & 100 & 100 & 100 \\
\hline Normal & 99 & 100 & 92 & 92 & 98 & 97 & 98 & 96 & 98 & 100 \\
\hline Chromatid break & 1 & - & - & 4 & 1 & - & 1 & - & - & - \\
\hline Chromosome break & - & - & - & 1 & - & 1 & - & - & - & - \\
\hline Deletion & - & - & - & 1 & - & - & - & - & 1 & - \\
\hline Ring & - & - & 3 & 1 & 1 & - & - & - & 1 & - \\
\hline Dicentric & - & - & 5 & 1 & - & 2 & - & 1 & - & - \\
\hline Fragment & - & - & - & - & - & - & - & 1 & - & - \\
\hline Gap & - & - & - & - & - & - & 1 & 1 & - & - \\
\hline Ploidy & - & - & - & - & - & - & - & 1 & - & - \\
\hline Endoreduplication & - & - & - & - & - & - & - & - & - & - \\
\hline Total aberrations & 1 & 0 & 8 & 8 & 2 & 3 & 1 & 1 & 2 & 0 \\
\hline Total aberrations $($ Mean \pm SD) & \multicolumn{2}{|c|}{$0.50 \pm 0.70$} & \multicolumn{2}{|c|}{$8.00 \pm 0.00^{*}$} & \multicolumn{2}{|c|}{$2.50 \pm 0.70$} & \multicolumn{2}{|c|}{$1.0 \pm 0.00$} & \multicolumn{2}{|c|}{$1.00 \pm 1.41$} \\
\hline Mitotic Index $($ Mean \pm SD $)$ & \multicolumn{2}{|c|}{$5.35 \pm 0.49$} & \multicolumn{2}{|c|}{$2.63 \pm 0.10^{*}$} & \multicolumn{2}{|c|}{$3.75 \pm 1.06$} & \multicolumn{2}{|c|}{$4.25 \pm 0.35$} & \multicolumn{2}{|c|}{$4.0 \pm 0.42$} \\
\hline
\end{tabular}

R: replicate; ${ }^{*} P<0.05$; MMC: mitomycin C; Ploidy, endoreduplication, gaps, and fragments are not considered as aberrations for calculations.

TABLE 4: Clastogenicity study upon short term exposure (4h) of NR-INF-02 in the presence of metabolic activation in human blood lymphocytes.

\begin{tabular}{|c|c|c|c|c|c|c|c|c|c|c|}
\hline \multirow[t]{2}{*}{ Treatment } & \multicolumn{2}{|c|}{ Vehicle control } & \multicolumn{2}{|c|}{$\begin{array}{c}\text { Positive control } \\
\text { B[a]P } \\
(20.00 \mu \mathrm{g} / \mathrm{mL})\end{array}$} & \multicolumn{2}{|c|}{$\begin{array}{c}\text { NR-INF-02 } \\
(2500.00 \mu \mathrm{g} / \mathrm{mL})\end{array}$} & \multicolumn{2}{|c|}{$\begin{array}{c}\text { NR-INF-02 } \\
(791.14 \mu \mathrm{g} / \mathrm{mL})\end{array}$} & \multicolumn{2}{|c|}{$\begin{array}{c}\text { NR-INF-02 } \\
(250.36 \mu \mathrm{g} / \mathrm{mL})\end{array}$} \\
\hline & $\mathrm{R} 1$ & $\mathrm{R} 2$ & $\mathrm{R} 1$ & $\mathrm{R} 2$ & $\mathrm{R} 1$ & $\mathrm{R} 2$ & $\mathrm{R} 1$ & $\mathrm{R} 2$ & $\mathrm{R} 1$ & $\mathrm{R} 2$ \\
\hline Total number of metaphase analyzed & 100 & 100 & 100 & 100 & 100 & 100 & 100 & 100 & 100 & 100 \\
\hline Normal & 100 & 97 & 93 & 89 & 100 & 96 & 97 & 97 & 98 & 98 \\
\hline Chromatid break & - & - & 3 & 2 & - & - & - & - & - & 1 \\
\hline Chromosome break & - & - & 1 & 1 & - & - & 1 & - & - & - \\
\hline Deletion & - & - & - & - & - & - & 1 & - & - & - \\
\hline Ring & - & - & 1 & 5 & - & 3 & - & 2 & - & - \\
\hline Dicentric & - & 1 & 1 & 1 & - & - & - & 1 & 1 & 1 \\
\hline Fragment & - & - & - & - & - & - & - & - & - & - \\
\hline Gap & - & - & - & - & - & - & 1 & - & - & - \\
\hline Ploidy & - & 2 & 1 & 2 & - & - & - & - & 1 & - \\
\hline Endoreduplication & - & - & - & - & - & 1 & - & - & - & - \\
\hline Total aberrations & 0 & 1 & 6 & 9 & 0 & 3 & 2 & 3 & 1 & 2 \\
\hline Total aberrations $($ Mean \pm SD) & \multicolumn{2}{|c|}{$0.50 \pm 0.70$} & \multicolumn{2}{|c|}{$7.50 \pm 2.12^{*}$} & \multicolumn{2}{|c|}{$1.50 \pm 2.12$} & \multicolumn{2}{|c|}{$2.50 \pm 0.70$} & \multicolumn{2}{|c|}{$1.50 \pm 0.70$} \\
\hline Mitotic Index $($ Mean \pm SD $)$ & \multicolumn{2}{|c|}{$3.20 \pm 0.14$} & \multicolumn{2}{|c|}{$2.60 \pm 0.13$} & \multicolumn{2}{|c|}{$2.70 \pm 0.28$} & \multicolumn{2}{|c|}{$3.0 \pm 0.28$} & \multicolumn{2}{|c|}{$3.45 \pm 0.35$} \\
\hline
\end{tabular}

R: replicate; ${ }^{*} P<0.05 ; \mathrm{B}[\mathrm{a}] \mathrm{P}$ : benzo[a]pyrene; Ploidy, endoreduplication, gaps, and fragments are not considered as aberrations for calculations.

a screening assay to predict carcinogens [32]. NR-INF-02 at dose range of $15.87-5000 \mu \mathrm{g} / \mathrm{mL}$ did not induce any significant increase in the revertant colonies both in the presence and absence of metabolic activation. These results confirmed the nonmutagenic activity in Salmonella strains like TA98 strain and TAMix strain. This is in agreement with the absence of genotoxicity of $C$. longa extracts tested in vitro by several researchers [6,35-38]. Moreover, a substantial lack of genotoxic activity is reported in the literature for extracts obtained from polysaccharide fraction of other species of the genus Curcuma, such as C. zedoaria [39]. Apart from lack of mutagenicity, antimutagenic property of C. longa extracts against several classical mutagens were reported $[35,40]$.

The study of DNA damage at the chromosomal level and micronuclei formation is a vital part of genetic toxicity screening [20, 21]. Chromosome aberration and 
TABLE 5: Clastogenicity study upon long term exposure (36h) of NR-INF-02 in the absence of metabolic activation in human blood lymphocytes.

\begin{tabular}{|c|c|c|c|c|c|c|c|c|c|c|}
\hline \multirow[t]{2}{*}{ Treatment } & \multicolumn{2}{|c|}{ Vehicle control } & \multicolumn{2}{|c|}{$\begin{array}{c}\text { Positive control } \\
\text { MMC } \\
(0.20 \mu \mathrm{g} / \mathrm{mL})\end{array}$} & \multicolumn{2}{|c|}{$\begin{array}{c}\text { NR-INF-02 } \\
(2500.00 \mu \mathrm{g} / \mathrm{mL})\end{array}$} & \multicolumn{2}{|c|}{$\begin{array}{c}\text { NR-INF-02 } \\
(791.14 \mu \mathrm{g} / \mathrm{mL})\end{array}$} & \multicolumn{2}{|c|}{$\begin{array}{c}\text { NR-INF-02 } \\
(250.36 \mu \mathrm{g} / \mathrm{mL})\end{array}$} \\
\hline & $\mathrm{R} 1$ & $\mathrm{R} 2$ & $\mathrm{R} 1$ & $\mathrm{R} 2$ & $\mathrm{R} 1$ & $\mathrm{R} 2$ & $\mathrm{R} 1$ & $\mathrm{R} 2$ & $\mathrm{R} 1$ & $\mathrm{R} 2$ \\
\hline Total number of metaphase analyzed & 100 & 100 & 100 & 100 & 100 & 100 & 100 & 100 & 100 & 100 \\
\hline Normal & 98 & 99 & 89 & 95 & 97 & 99 & 96 & 100 & 100 & 100 \\
\hline Chromatid break & - & - & 4 & 2 & - & - & 1 & - & - & - \\
\hline Chromosome break & - & - & - & - & - & - & - & - & - & - \\
\hline Deletion & - & - & 4 & 3 & 1 & - & - & - & - & - \\
\hline Ring & 1 & 1 & 1 & - & 1 & 1 & 1 & - & - & - \\
\hline Dicentric & - & - & 1 & - & - & - & 2 & - & - & - \\
\hline Fragment & - & - & - & - & 1 & - & - & - & - & - \\
\hline Gap & - & - & - & - & - & - & - & - & - & - \\
\hline Ploidy & 1 & - & 1 & - & - & - & - & - & - & - \\
\hline Endoreduplication & - & - & - & - & - & - & - & - & - & - \\
\hline Total aberrations & 1 & 1 & 10 & 5 & 2 & 1 & 4 & 0 & 0 & 0 \\
\hline Total aberrations $($ Mean \pm SD) & \multicolumn{2}{|c|}{$1.00 \pm 0.00$} & \multicolumn{2}{|c|}{$7.50 \pm 3.53^{*}$} & \multicolumn{2}{|c|}{$1.50 \pm 0.70$} & \multicolumn{2}{|c|}{$2.00 \pm 2.82$} & \multicolumn{2}{|c|}{$0.00 \pm 0.00$} \\
\hline Mitotic Index $($ Mean \pm SD $)$ & \multicolumn{2}{|c|}{$3.41 \pm 0.41$} & \multicolumn{2}{|c|}{$2.15 \pm 0.07^{*}$} & \multicolumn{2}{|c|}{$2.86 \pm 0.23$} & \multicolumn{2}{|c|}{$2.85 \pm 0.28$} & \multicolumn{2}{|c|}{$3.01 \pm 0.01$} \\
\hline
\end{tabular}

R: replicate; ${ }^{*} P<0.05$; MMC: mitomycin C; Ploidy, endoreduplication, gaps, and fragments are not considered as aberrations for calculations.

TABLE 6: Effect of NR-INF-02 on micronucleus induction in CHOK1 cells.

\begin{tabular}{lcc}
\hline Treatment $(\mu \mathrm{g} / \mathrm{mL})$ & $\begin{array}{c}\text { MN-BN cells }(\%) \\
\text { Mean } \pm \text { SD }\end{array}$ & $\begin{array}{c}\text { CBPI } \\
\text { Wean } \pm \text { SD }\end{array}$ \\
\hline \multicolumn{3}{c}{ Without S9 short term exposure (4h) } \\
Vehicle control & $0.15 \pm 0.07$ & $1.80 \pm 0.01$ \\
NR-INF-02 $(250.36 \mu \mathrm{g} / \mathrm{mL})$ & $0.00 \pm 0.00$ & $1.78 \pm 0.03$ \\
NR-INF-02 $(791.14 \mu \mathrm{g} / \mathrm{mL})$ & $0.00 \pm 0.00$ & $1.78 \pm 0.01$ \\
NR-INF-02 $(2500.00 \mu \mathrm{g} / \mathrm{mL})$ & $0.00 \pm 0.00$ & $1.77 \pm 0.01$ \\
Positive control & $0.50 \pm 0.14^{*}$ & $1.66 \pm 0.03^{*}$ \\
MMC $(0.2 \mu \mathrm{g} / \mathrm{mL})$ & With S9 short term exposure $(4 \mathrm{~h})$ \\
\hline & $0.00 \pm 0.00$ & $1.80 \pm 0.01$ \\
Vehicle control & $0.05 \pm 0.07$ & $1.80 \pm 0.04$ \\
NR-INF-02 $(250.36 \mu \mathrm{g} / \mathrm{mL})$ & $0.00 \pm 0.00$ & $1.80 \pm 0.01$ \\
NR-INF-02 $(791.14 \mu \mathrm{g} / \mathrm{mL})$ & $0.00 \pm 0.00$ & $1.80 \pm 0.04$ \\
NR-INF-02 $(2500.0 \mu \mathrm{g} / \mathrm{mL})$ & $1.6 \pm 0.28^{*}$ & $1.70 \pm 0.03$ \\
Positive control & Without S9 long term exposure $(18 \mathrm{~h})$ \\
B[a]P $(20.0 \mu \mathrm{g} / \mathrm{mL})$ & $0.00 \pm 0.00$ & $1.86 \pm 0.00$ \\
\hline & $0.10 \pm 0.00$ & $1.87 \pm 0.02$ \\
Vehicle control & $0.00 \pm 0.00$ & $1.86 \pm 0.01$ \\
NR-INF-02 $(250.36 \mu \mathrm{g} / \mathrm{mL})$ & $0.15 \pm 0.07$ & $1.84 \pm 0.01$ \\
NR-INF-02 $(791.14 \mu \mathrm{g} / \mathrm{mL})$ & $4.55 \pm 0.78^{*}$ & $1.58 \pm 0.04^{*}$ \\
NR-INF-02 $(2500.0 \mu \mathrm{g} / \mathrm{mL})$ & & \\
Positive control & & \\
MMC $(0.2 \mu \mathrm{g} / \mathrm{mL})$ & & \\
\hline
\end{tabular}

${ }^{*} P<0.05$; MMC: mitomycin C; B[a]P: benzo[a]pyrene.

micronucleus tests were carried out with NR-INF-02 using peripheral blood lymphocytes and $\mathrm{CHO}-\mathrm{K} 1$ cells, respectively. The effect of NR-INF-02 on dividing cell population was examined by studying mitotic index and CBPI in peripheral blood lymphocytes and CHO-K1 cells, respectively. The mitotic index is used to quantify differences in cell division when an environmental parameter is changed [20]. CBPI indicates the number of cell cycles per cell during the period of exposure to cytochalasin B [21]. Treatment effect of NR-INF-02 on MI and CBPI indicated that cells did not differ in their capability to divide in comparison to vehicle control. Also, NR-INF-02 did not induce significant chromosome aberrations and micronuclei formation in mammalian cells. These results are in accordance with the absence of clastogenic effect of $C$. longa and C. zedoaria extracts tested and reported previously [39-42]. In addition, anticlatsogenic effect of $C$. longa was observed against benzo (a) pyrene induced micronucleus in mice and these results indicated that components of $C$. longa could help in cancer chemoprevention $[35,40]$.

Acute oral toxicity data on NR-INF-02 is used to satisfy hazard classification and labelling requirements for its risk assessment in human health and environment [43]. In the present study, acute oral toxicity assessment of NR-INF02 did not cause mortality, abnormal clinical signs or any significant pathological changes at a dose level of $5000 \mathrm{mg} / \mathrm{kg}$ body weight. Also, the overall body weight gain was found to be normal in all the treated rats and hence resulted in labelling the NR-INF-02 as unclassified in the hazard category according to Globally Harmonised System [22]. Current acute oral toxicity study results are in agreement with previous study which demonstrated no toxic effects upon ingestion of turmeric extracts by rats [44].

In contrary, curcumin induced significant increases in sister chromatid exchanges and chromosomal aberrations 
TABLE 7: Clinical signs and gross pathology findings in rats after treatment with NR-INF-02.

\begin{tabular}{|c|c|c|c|c|c|}
\hline \multirow{2}{*}{ Study } & \multirow{2}{*}{ Dose $(\mathrm{g} / \mathrm{kg})$} & \multicolumn{2}{|c|}{ Cage side observations } & \multirow{2}{*}{ Total number of animals } & \multirow{2}{*}{ Gross pathology findings } \\
\hline & & Observed signs & Period of signs in days, from-to & & \\
\hline Sighting $(n=1)$ & 5 & Nil & $0-14$ & 1 & No abnormality detected \\
\hline Main $(n=4)$ & 5 & Nil & $0-14$ & 4 & No abnormality detected \\
\hline
\end{tabular}

$n$ : number of animals.

TABLE 8: Effect of NR-INF-02 on body weight and percent body weight gain in rats.

\begin{tabular}{|c|c|c|c|c|c|c|c|}
\hline \multirow{2}{*}{ Study } & \multirow{2}{*}{ Dose (g/kg) } & \multicolumn{3}{|c|}{ Body weight } & \multicolumn{3}{|c|}{ Percent body weight gain } \\
\hline & & Day 0 & Day 7 & Day 14 & Days $0-7$ & Days 7-14 & Days 0-14 \\
\hline Sighting $(n=1)$ & 5 & 163 & 188 & 204 & 15.34 & 8.51 & 25.15 \\
\hline Main $(n=4)$ & 5 & 163.75 & 195.75 & 216.25 & 19.54 & 10.47 & 32.06 \\
\hline
\end{tabular}

$n$ : number of animals.

in cultured Chinese hamster ovary cells [36]. In addition, hepatotoxicity was observed in rodents fed turmeric for chronic duration $[45,46]$. National Toxicology Program conducted detailed two year safety study; results indicated an equivocal evidence of carcinogenic activity, increased incidences of ulcers, hyperplasia, and inflammation of the forestomach, cecum, and colon in rats of turmeric oleoresin exposed groups [36]. Differences on results observed between the current study and published results might be due to variation in phytochemical composition of test items.

NR-INF-02 is a polysaccharide containing extract and is a complex mixture of natural substances. As evident in our results, NR-INF-02 contains acceptable pharmacopeial limits for microbes, heavy metals, pesticides, and aflatoxin contents which further confirm the quality assurance of this extract.

The use of genotoxicity testing is to determine C. longa extract influences genetic material or may cause cancer. The results confirmed the genotoxic safety of $C$. longa extract in a battery of genotoxicity tests. Acute oral toxicity data on C. longa extract is used to satisfy hazard classification and labelling requirements for its risk assessment in human health and environment [43]. In the present study, acute oral toxicity assessment of $C$. longa extract did not cause mortality, abnormal clinical signs, or any significant pathological changes upto the dose level of $5000 \mathrm{mg} / \mathrm{kg}$ body weight. Also, the overall body weight gain was found to be normal in all the treated rats and hence resulted in labelling the $C$. longa extract as unclassified in the hazard category according to Globally Harmonised System [22]. Also, clinical effective dose of NR-INF-02 for pain management in human osteoarthritis patients was achieved at $1 \mathrm{~g} /$ day with no adverse effects after daily oral intake of 42 days [17].

\section{Conclusion}

In conclusion, polysaccharide extract of $C$. longa was found to be non-mutagenic to $S$. typhimurium strains like TA98 strain and TAMix strain. C. longa did not increase the occurrence of structural chromosomal aberrations in human peripheral blood lymphocytes and micronucleus formation in CHO-K1 cells. Also, it was found to be safe after oral administration as a single dose to female albino Wistar rats up to $5 \mathrm{~g} / \mathrm{kg}$ body weight. Therefore, polysaccharide extract from rhizomes of C. longa is not mutagenic in the tested standard battery of genotoxicity tests and found to be safe in an acute oral toxicity study.

\section{Conflict of Interests}

Trade mark of the product under study is owned by the company for which all the authors work.

\section{Disclosure}

This research received no specific grant from any funding agency in the public and not-for-profit sectors.

\section{References}

[1] M. Akram, Shahab-Uddin, A. Ahmed et al., "Curcuma longa and curcumin: a review article," Romanian Journal of Biology, vol. 55, pp. 65-70, 2010.

[2] The Ayurvedic Pharmacopoeia of India, part 1, vol. 8, The Controller of Publications, Civil Lines, Delhi, India, 1st edition, 2011.

[3] N. Chainani-Wu, "Safety and anti-inflammatory activity of curcumin: a component of tumeric (Curcuma longa)," Journal of Alternative and Complementary Medicine, vol. 9, no. 1, pp. 161168, 2003.

[4] M. H. Chen, M. Y. Lee, J. J. Chuang et al., "Curcumin inhibits HCV replication by induction of heme oxygenase-1 and suppression of AKT,' International Journal of Molecular Medicine, vol. 30, pp. 1021-1028, 2012.

[5] J.-L. Ji, X.-F. Huang, and H.-L. Zhu, "Curcumin and its formulations: potential anti-cancer agents," Anti-Cancer Agents in Medicinal Chemistry, vol. 12, no. 3, pp. 210-218, 2012.

[6] V. B. Liju, K. Jeena, and R. Kuttan, "Acute and subchronic toxicity as well as mutagenic evaluation of essential oil from turmeric (Curcuma longa L)," Food and Chemical Toxicology, vol. 53, pp. 52-61, 2012.

[7] S. Balaji and B. Chempakam, "Toxicity prediction of compounds from turmeric (Curcuma longa L)," Food and Chemical Toxicology, vol. 48, no. 10, pp. 2951-2959, 2010.

[8] J. Joshi, S. Ghaisas, A. Vaidya et al., "Early human safety study of turmeric oil (Curcuma longa oil) administered orally in healthy 
volunteers," Journal of Association of Physicians of India, vol. 51, pp. 1055-1060, 2003.

[9] S. Mohankumar and J. R. McFarlane, "An aqueous extract of Curcuma longa (turmeric) rhizomes stimulates insulin release and mimics insulin action on tissues involved in glucose homeostasis in vitro," Phytotherapy Research, vol. 25, no. 3, pp. 396-401, 2011.

[10] S. S. Deshpande, A. D. Ingle, and G. B. Maru, "Chemopreventive efficacy of curcumin-free aqueous turmeric extract in 7,12dimethylbenz[a]anthracene-induced rat mammary tumorigenesis," Cancer Letters, vol. 123, no. 1, pp. 35-40, 1998.

[11] Z. F. Yu, L. D. Kong, and Y. Chen, "Antidepressant activity of aqueous extracts of Curcuma longa in mice," Journal of Ethnopharmacology, vol. 83, no. 1-2, pp. 161-165, 2002.

[12] R. Selvam, L. Subramanian, R. Gayathri, and N. Angayarkanni, "The anti-oxidant activity of turmeric (Curcuma longa)," Journal of Ethnopharmacology, vol. 47, no. 2, pp. 59-67, 1995.

[13] J. Anbu Jeba Sunilson, R. Suraj, G. Rejitha, K. Anandarajagopal, A. V. Anita Gnana Kumari, and P. Promwichit, "In vitro antimicrobial evaluation of Zingiber officinale, Curcuma longa and Alpinia galanga extracts as natural food preservatives," American Journal of Food Technology, vol. 4, no. 5, pp. 192-200, 2009.

[14] R. K. Mishra and S. K. Singh, "Reversible antifertility effect of aqueous rhizome extract of Curcuma longa L. in male laboratory mice," Contraception, vol. 79, no. 6, pp. 479-487, 2009.

[15] L. Subramanian and R. Selvam, "Prevention of CCl4-Induced hepatotoxicity by aqueous extract of turmeric," Nutrition Research, vol. 19, no. 3, pp. 429-441, 1999.

[16] G. G. L. Yue, B. C. L. Chan, P.-M. Hon et al., "Immunostimulatory activities of polysaccharide extract isolated from Curcuma longa," International Journal of Biological Macromolecules, vol. 47, no. 3, pp. 342-347, 2010.

[17] K. Madhu, K. Chanda, and Saji, "Safety and efficacy of Curcuma longa extract in the treatment of painful knee osteoarthritis: a randomized placebo controlled trial," Inflammopharmacology, vol. 21, pp. 129-136, 2013.

[18] C. V. Chandrasekaran, K. Sundarajan, R. J. Edwin et al., "Immune-stimulatory and anti-inflammatory activities of Curcuma longa extract and its polysaccharide fraction," Pharmacognosy Research, vol. 5, pp. 71-79, 2013.

[19] OECD Guidelines for Testing of Chemicals, "Bacterial Reverse Mutation Test, No. 471," Organisation for Economic Cooperation and Development: Paris, France, 1997.

[20] OECD Guidelines for Testing of Chemicals, "In vitro Mammalian Chromosomal Aberration Test, No. 473," Organisation for Economic Co-operation and Development: Paris, France, 1997.

[21] OECD Guidelines for Testing of Chemicals, "In vitro Micronucleus Test, No. 487," Organisation for Economic Co-operation and Development: Paris, France, 2004.

[22] OECD Guidelines for Testing of Chemicals, "Acute Oral Toxicity-Fixed Dose Procedure, No 420," Organisation for Economic Co-operation and Development: Paris, France, 2001.

[23] D. Blanco Gomis, D. Muro Tamayo, and J. Mangas Alonso, "Determination of monosaccharides in cider by reversed-phase liquid chromatography," Analytica Chimica Acta, vol. 436, no. 1, pp. 173-180, 2001.

[24] USP36-NF31, United States Pharmacopoeia 36-National Formulary 31, Rockville, Md, USA, 2013.

[25] British Pharmacopeia, 2013.
[26] ICH, "Harmonised Tripartite Guideline Stability Testing of New Drug Substances and Products," Q1A (R2), 2003.

[27] S. Flückiger-Isler, M. Baumeister, K. Braun et al., "Assessment of the performance of the Ames II assay: a collaborative study with 19 coded compounds," Mutation Research, vol. 558, no. 1-2, pp. 181-197, 2004.

[28] C. V. Chandrasekaran, P. Thiyagarajan, K. Sundarajan et al., "Evaluation of the genotoxic potential and acute oral toxicity of standardized extract of Andrographis paniculata (KalmCold)," Food and Chemical Toxicology, vol. 47, no. 8, pp. 1892-1902, 2009.

[29] C. V. Chandrasekaran, K. Sundarajan, K. David, and A. Agarwal, "In vitro efficacy and safety of poly-herbal formulations," Toxicology in Vitro, vol. 24, no. 3, pp. 885-897, 2010.

[30] C. V. Chandrasekaran, K. Sundarajan, A. Gupta, H. S. Srikanth, J. Edwin, and A. Agarwal, "Evaluation of the genotoxic potential of standardized extract of Glycyrrhiza glabra (GutGard)," Regulatory Toxicology and Pharmacology, vol. 61, no. 3, pp. 373-380, 2011.

[31] C. V. Chandrasekaran, H. S. Srikanth, M. S. Anand et al., "Evaluation of the mutagenic potential and acute oral toxicity of standardized extract of Ocimum sanctum (OciBest)," Human and Experimental Toxicology, vol. 32, pp. 992-1004, 2013.

[32] D. M. Maron and B. N. Ames, "Revised methods for the Salmonella mutagenicity test," Mutation Research, vol. 113, no. 3-4, pp. 173-215, 1983.

[33] J. R. K. Savage, "Classification and relationships of induced chromosomal structural changes," Journal of Medical Genetics, vol. 13, no. 2, pp. 103-122, 1976.

[34] M. Fenech, "The in vitro micronucleus technique," Mutation Research, vol. 455, no. 1-2, pp. 81-95, 2000.

[35] M. A. Azuine, J. J. Kayal, and S. V. Bhide, "Protective role of aqueous turmeric extract against mutagenicity of direct-acting carcinogens as well as benzo[a]pyrene-induced genotoxicity and carcinogenicity," Journal of Cancer Research and Clinical Oncology, vol. 118, no. 6, pp. 447-452, 1992.

[36] National Toxicology Program, "NTP Toxicology and Carcinogenesis Studies of Turmeric Oleoresin (CAS No. 8024-37-1) (Major Component 79\%-85\% Curcumin, CAS No. 458-37-7) in F344/N Rats and B6C3F1 Mice (Feed Studies)," National Toxicology Program Technical Report Series, vol. 427, pp. 1-275, 1993.

[37] H. R. Khorram Khorshid, Y. A. Novitsky, M. Abdollahi et al., "Studies on potential mutagenic and genotoxic activity of Setarud," Daru, vol. 16, no. 4, pp. 223-228, 2008.

[38] M. Nagabhushan and S. V. Bhide, "Nonmutagenicity of curcumin and its antimutagenic action versus chili and capsaicin," Nutrition and Cancer, vol. 8, no. 3, pp. 201-210, 1986.

[39] K. I. Kim, J. W. Kim, B. S. Hong et al., "Antitumor, genotoxicity and anticlastogenic activities of polysaccharide from Curcuma zedoaria," Molecules and Cells, vol. 10, no. 4, pp. 392-398, 2000.

[40] G. K. Jayaprakasha, B. S. Jena, P. S. Negi, and K. K. Sakariah, "Evaluation of antioxidant activities and antimutagenicity of turmeric oil: a byproduct from curcumin production," Journal of Biosciences, vol. 57, no. 9-10, pp. 828-835, 2002.

[41] K. Hastak, N. Lubri, S. D. Jakhi et al., "Effect of turmeric oil and turmeric oleoresin on cytogenetic damage in patients suffering from oral submucous fibrosis," Cancer Letters, vol. 116, no. 2, pp. 265-269, 1997.

[42] V. Alaxmi, "Genetic effects of turmeric and curcumin in mice and rats," Mutation Research, vol. 79, no. 2, pp. 125-132, 1980. 
[43] OECD. Guidance document on Acute Oral Toxicity Testing, "OECD Environment, Health and Safety Publications Series on Testing and Assessment, No.24," Organisation for Economic Co-operation and Development: Paris, Frace, 2001.

[44] T. N. Bhavani Shankar, N. V. Shantha, and H. P. Ramesh, "Toxicity studies on turmeric (Curcuma longa): acute toxicity studies in rats, guinea pigs \& monkeys," Indian Journal of Experimental Biology, vol. 18, no. 1, pp. 73-75, 1980.

[45] S. V. Kandarkar, S. S. Sawant, A. D. Ingle, S. S. Deshpande, and G. B. Maru, "Subchronic oral hepatotoxicity of turmeric in mice-Histopathological and ultrastructural studies," Indian Journal of Experimental Biology, vol. 36, no. 7, pp. 675-679, 1998.

[46] S. S. Deshpande, V. S. Lalitha, A. D. Ingle, A. S. Raste, S. G. Gadre, and G. B. Maru, "Subchronic oral toxicity of turmeric and ethanolic turmeric extract in female mice and rats," Toxicology Letters, vol. 95, no. 3, pp. 183-193, 1998. 

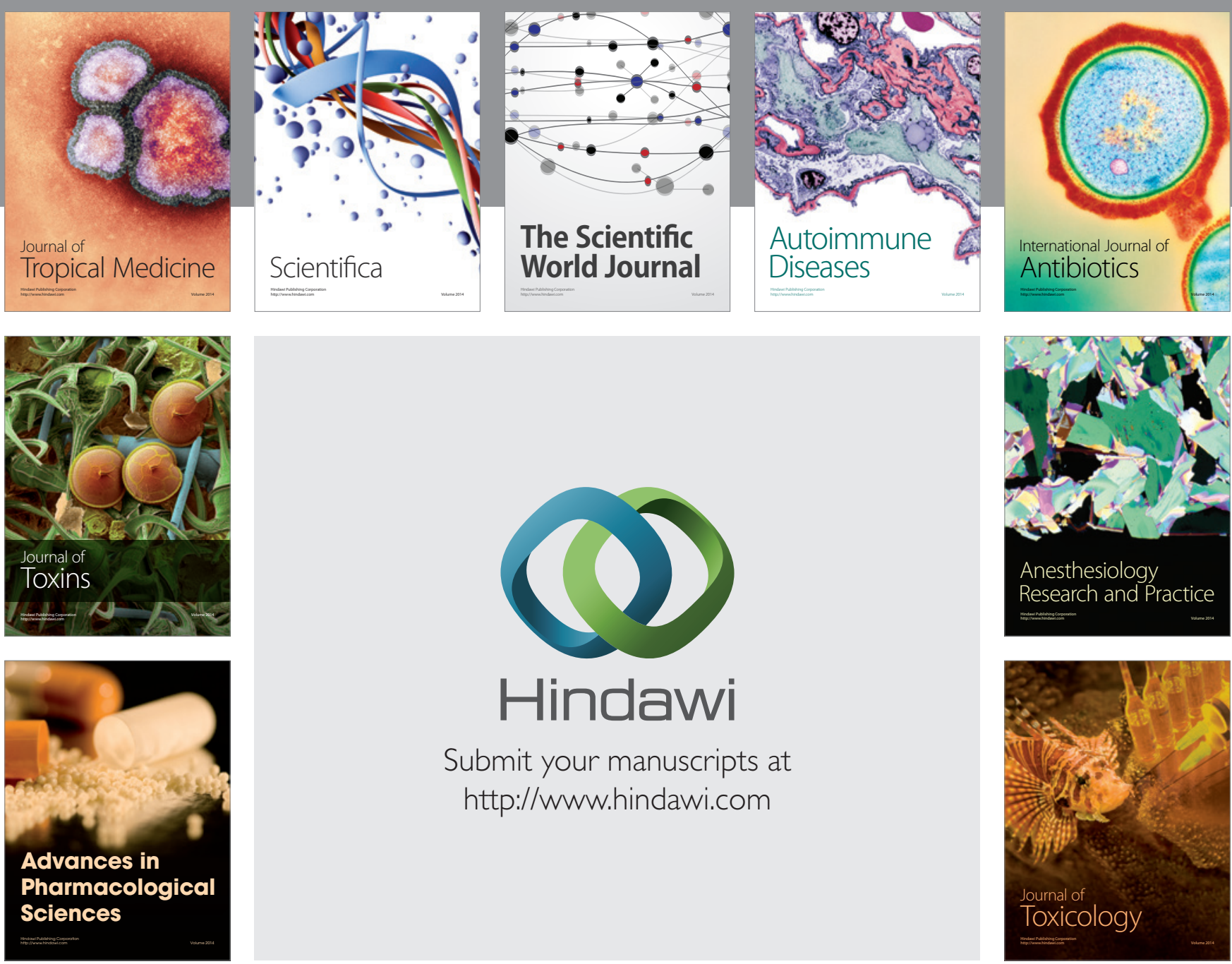

\section{Hindawi}

Submit your manuscripts at

http://www.hindawi.com
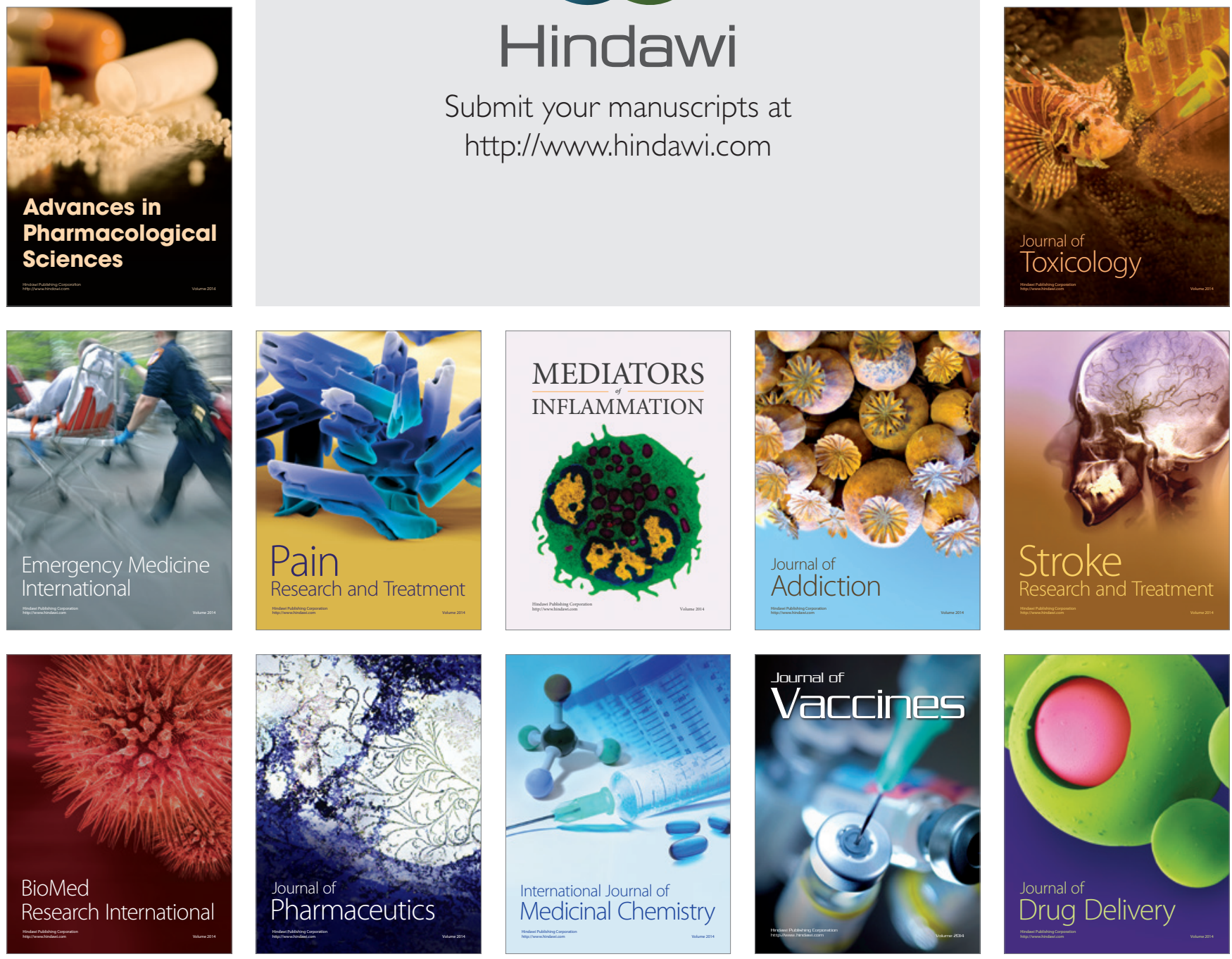